\title{
AEROMAGNETIC MAP OF THE SPRINGFIELD SOUTH QUADRANGLE HAMPDEN COUNTY, MASSACHUSETTS, AND HARTFORD AND TOLLAND COUNTIES, CONNECTICUT
}

\author{
GEOPHYSICAL INVESTIGATIONS \\ MAP GP-632
}

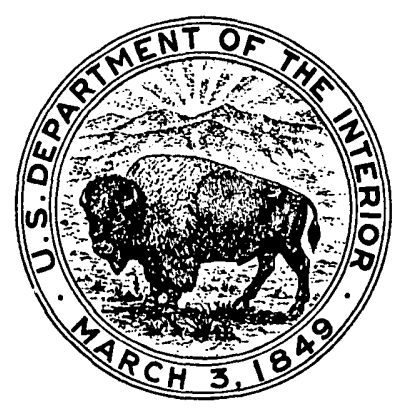

PUBLISHED BY THE U.S. GEOLOGICAL SURVEY 